\title{
AN EFFICIENT THREE COMPONENT ONE-POT SYNTHESIS OF -1,2,3,4-TETRAHYDRO-4-OXO- 6-(5-SUBSTITUTED 2-PHENYL-1H-INDOL-3-YL)-2-THIOXOPYRIMIDINE-5-CARBONITRILE AS ANTIMICROBIAL AND ANTITUBERCULAR AGENTS
}

\author{
PRABHAKER WALMIK* \\ Department of Post-Graduate Studies and Research in Chemistry, Sahyadri Science College, Kuvempu University, Shimoga, Karnataka, \\ India. Email: prabhakarchavan7@gmail.com.com
}

Received: 17 August 2020, Revised and Accepted: 31 October 2020

ABSTRACT

Objective: The objective of the study was to synthesis of 1,2,3,4-tetrahydro-4-oxo-6-(5-substituted 2-phenyl-1H-indol-3-yl)-2-thioxopyrimidine-5carbonitrile derivatives (4a-c).

Methods: The structures of all these unknown compounds have been confirmed with the help of physical and spectral techniques such as IR, ${ }^{1} \mathrm{H}$, and ${ }^{13} \mathrm{C}$ NMR and mass spectral data and these newly synthesized compounds were evaluated for in-vitro antimicrobial and antitubercular activities.

Results: Screening studies have demonstrated that the newly synthesized compound 4a exhibited promising antimicrobial and antitubercular properties.

Conclusion: The final results revealed that compound 4a exhibited promising antimicrobial and antitubercular properties when compared to the standard drugs.

Keywords: Indole, Thioxopyrimidine, Antimicrobial, Antitubercular activities.

(C) 2021 The Authors. Published by Innovare Academic Sciences Pvt Ltd. This is an open access article under the CC BY license (http://creativecommons.org/ licenses/by/4.0/) DOI: http://dx.doi.org/10.22159/ajpcr.2021v14i1.39418. Journal homepage: https://innovareacademics.in/journals/index.php/ajpcr

\section{INTRODUCTION}

Heterocyclic compounds have been proved to be the most useful ones due to their possible practical applications. Heterocyclic compounds exhibits wide range of biological activities such as antibacterial and antifungal activities [1-6]. One-pot multi-component organic reactions (MCORs) are important and attractive due to the formation of multibonds in one pot, high atom economy, mild and simplified conditions, facile execution, and generation of complex product from a single operation process to available starting materials. MCORs are now being tuned for synthesizing various heterocyclic compounds due to their diverse biological activities $[7,8]$.

The indole derivative has been reported to possess a wide variety of biological activities, namely, anti-inflammatory $[9,10]$, anticonvulsant [11], cardiovascular [12], antibacterial [13], cyclooxygenase-2 inhibitor [14], and antiviral [15]. The significant contribution of many derivatives of indole in the development of medicinal chemistry is well recognized. Serotonin, known for its vasoconstrictor principle [16], plays a vital role as a neurotransmitter and in psychosis. Pyridine is used as a pioneer for pharmaceuticals, agrochemicals, and it is used as organic solvent and reagent. It plays a key role in mobilize both chemical and biological systems. Compounds containing fused pyrimidine ring has attracted much attention of researcher due to their wide range of biological activities, particularly in cancer and virus research [16]. Furthermore, substituted pyrimidine at position-2 or -4 with an amino group is known as pharmacophores in several structure-based drug design approaches in medicinal chemistry [17].

In addition to this, various analogs of pyrimidines have been found to possess antibacterial [18], antifungal [19], antileishmanial [20], anti-inflammatory [21], and analgesic [22] activities. Many thienopyrimidines are found to exhibit a variety of biological activities, including anti-inflammatory [23], antimicrobial [24], and analgesic [25] properties. In view of the above observations and in continuation of our research work on the synthesis of biologically active molecules [26-33]. In the present investigation, we planned to synthesize of indole and pyrimidine nucleus embedded in one frame (indolyl-pyrimidine) to get a more potent molecule and testing for anti-microbial and antianticancer activities.

\section{METHODS}

All the reagents were obtained commercially and used by further purification using standard procedures. Melting points were determined by an open capillary method and are uncorrected. Purity of the compounds was checked by thin-layer chromatography (TLC) using silica gel-G coated Al plates (Merck) and spots were visualized by exposing the dry plates in iodine vapors. The IR (KBr pellet) spectra were recorded on a Perkin-Elmer (Spectrum ONE) Fourier-transform infrared (FT-IR) Spectrometer. The ${ }^{1} \mathrm{H}$ and ${ }^{13} \mathrm{C}$ NMR (dimethyl sulfoxide [DMSO]-d $d_{6}$ spectra were recorded with a BRUKER NMR 500 and $125 \mathrm{MHz}$ spectrometers, and the chemical shift values are expressed in $\mathrm{ppm}(\delta$ scale) using tetramethylsilane as an internal standard. The mass spectral measurements were carried out by electron impact method on JEOL GC mate spectrometer at $70 \mathrm{eV}$. Elemental analyses were performed on flash EA 1112 series elemental analyzer.

General procedure for the synthesis of (5-Substituted 2-phenyl-1Hindol-3-carboxaldehydes $1 \mathrm{a}-\mathrm{c}$ was prepared by the following literature method [34].

General procedure for the synthesis of 1,2,3,4-tetrahydro-4-oxo-6-(5substituted 2-phenyl-1 $H$-indol-3-yl)-2-thioxopyrimidine-5-carbonitrile (4a-c): Appropriate mixture of 5-substituted 2-phenyl indole-3carboxadehydes ( $1 \mathrm{a}-\mathrm{c})$ ( 0.01 mole), ethyl cyanoacetate 2 (0.01 mole), and thiourea $3(0.01$ mole $)$ in ethanol $(25 \mathrm{~mL})$ containing and potassium carbonate $(0.01$ mole) was taken in round bottom flask, refluxed on water bath for 7-8 h. The reaction completion of was monitored by TLC. 
Then, the reaction mixture was poured into ice-cold water and acidified with acetic acid; then, the precipitate occurs which was filtered, washed with water, dried, and recrystallized with ethanol was to afforded 4a-c.

1,2,3,4-tetrahydro-4-oxo-6-(5-chloro 2-phenyl-1H-indol-3-yl)-2thioxopyrimidine-5-carbonitrile (4a): Yield: 89\%; M.p.: $229-30^{\circ} \mathrm{C} ; \mathrm{R}_{\mathrm{f}}$ 0.91 ethyl acetate: pet ether (1:1) mixture; FT-IR (KBr) $\left(\mathrm{cm}^{-1}\right): 3340$ (CO-NH-CS), 3319 (NH-CS) 3101 (indole-NH), 2170 (CN), 1665 (CO), 1102 (CS); ${ }^{1} \mathrm{H}$ NMR (DMSO-d $)$ : $\delta: 12.01$ (s, 1H, indole NH), $10.11(\mathrm{~s}$, 1H,CO-NH-CS), 9.96 (s, 1H, NH-CS),7.30-7.71 (m, 8H, Ar-H); ${ }^{13} \mathrm{C}$ NMR (DMSO-d): 174.3, 169.8, 164.4, 133.9, 133.8, 128.8, 128.5, 127.1, 126.6, $123.3,121.3,119.5,115.9,112.8,104$ and 80.6; MS (EI) m/z 378.034 $\left(\mathrm{M}^{+}\right)$, $380.036\left(\mathrm{M}^{+}+2\right)$; Anal. Calcd. for $\mathrm{C}_{19} \mathrm{H}_{11} \mathrm{~N}_{4} \mathrm{OSCl}$ (380.036), C, 60.24, H, 2.93, N, 14.19. Found: C, 60.31, H, 2.90, N, 14.16\%

1,2,3,4-tetrahydro-4-oxo-6-(5-methyl

2-phenyl-1H-indol-3-yl)-2thioxopyrimidine-5-carbonitrile (4b): Yield: $86 \%$; M.p.: $205-06^{\circ} \mathrm{C} ; \mathrm{R}_{\mathrm{f}}$ 0.86 ethyl acetate: pet ether (1:1) mixture; FT-IR $(\mathrm{KBr})\left(\mathrm{cm}^{-1}\right): 3348$ (CO-NH-CS), 3325 (NH-CS) 3102 (indole-NH), 2170 (CN), 1659 (CO), 1108 (CS); ${ }^{1} \mathrm{H}$ NMR (DMSO-d ): $\delta: 12.08(\mathrm{~s}, 1 \mathrm{H}$, indole $\mathrm{NH}), 10.08(\mathrm{~s}$, 1H,CO-NH-CS), 10.01 (s, 1H, NH-CS),7.26-7.61 (m, 8H, Ar-H), 2.47 (s, $3 \mathrm{H}, \mathrm{CH}_{3}$ ); ${ }^{13} \mathrm{C}$ NMR (DMSO-d $)$ : 174.1, 169.6, 164.3, 133.8, 133.4, 128.5, 128.2, 127.0, 126.8, 123.5, 121.5, 119.6, 116.1, 112.2, 105, 80.6 and 23.6; MS (EI) m/z $358\left(\mathrm{M}^{+}\right.$); Anal. Calcd. for $\mathrm{C}_{20} \mathrm{H}_{14} \mathrm{~N}_{4} \mathrm{OS}$ (358.089), C, 67.02, H, 3.94, N, 15.63. Found: C, 67.03, H, 3.92, N, 15.68\%.

1,2,3,4 - tetrahydro-4-oxo-6 - (2 - phenyl- $1 H$-indol-3-yl) - 2 thioxopyrimidine-5-carbonitrile (4c): Yield: $88 \%$; M.p.: $196-97^{\circ} \mathrm{C}$; $\mathrm{R}_{\mathrm{f}}$ 0.90 ethyl acetate: pet ether (1:1) mixture; FT-IR (KBr) $\left(\mathrm{cm}^{-1}\right): 3350$ (CO-NH-CS), 3327 (NH-CS) 3106 (indole-NH), 2179 (CN), 1662 (CO), 1105 (CS); ${ }^{1} \mathrm{H}$ NMR (DMSO-d 6 ): $\delta: 12.05$ (s, 1H, indole NH), 10.09 (s, 1H,CO-NH-CS), 10.01 (s, 1H, NH-CS),7.31-7.70 (m, 9H, Ar-H); ${ }^{13} \mathrm{C}$ NMR $($ DMSO-d $)$ ): 175.2, 169.2, 165.2, 134.8, 133.1, 129.1, 128.1, 127.2, 126.5, 123.1, 121.4, 119.5, 116.4, 112.3, 105.1, 80.6; MS (EI) m/z $344\left(\mathrm{M}^{+}\right)$; Anal. Calcd. for $\mathrm{C}_{19} \mathrm{H}_{12} \mathrm{~N}_{4}$ OS (344.073), C, 66.26, $\mathrm{H}, 3.51, \mathrm{~N}, 16.27$. Found: C, 66.30, H, 3.48, N, 16.22\%.

\section{In-vitro antimicrobial activity}

The in-vitro antimicrobial activity of all the synthesized compounds (4a-c) was carried out by broth microdilution method [35] in dimethylformamide at concentrations 500, 250, 125, and $62.5 \mu \mathrm{g} / \mathrm{mL}$. Mueller-Hinton broth was used as a nutrient medium to growth and dilutes the compound suspension for the test bacteria and Sabouraud Dextrose broth used for fungal nutrition. Inoculums size for test strain was adjusted to $10^{8}$ colony-forming unit per milliliter by comparing the turbidity. The strain employed for the activity was procured from the Department of Biotechnology, Sahyadri Science College, Shimoga.

The compounds (4a-c) were screened for their antibacterial activity against Escherichia coli (MTCC-723), Staphylococcus aureus (ATCC29513), Klebsiella pneumonia (NCTC-13368), and Pseudomonas aeruginosa (MTCC-1688), as well antifungal activity against Aspergillus oryzae (MTCC-3567 ${ }^{\mathrm{T}}$ ), Aspergillus niger (MTCC-281), Aspergillus flavus (MTCC-1973), and Aspergillus terreus (MTCC-1782). DMSO used as a vehicle to get the desired concentration of compounds to test upon microbial strains. The lowest concentration which showed no visible growth after spot subculture was considered as minimum inhibitory concentration (MIC) for each compound. The standard antibiotic used for comparison in the present study was gentamycin for evaluating for antibacterial activity and fluconazole for antifungal activity. The protocols are summarized in (Table 1).

\section{Antitubercular activity using Alamar Blue Dye}

The antitubercular activity of compounds (4a-c) was assessed

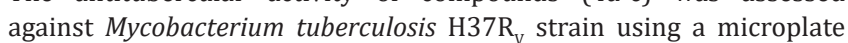
Alamar blue dye assay [36]. Briefly, $200 \mu \mathrm{L}$ of sterile deionzed water was added to all outer perimeter wells of sterile 96 wells plate to minimize evaporation of medium in the test wells during incubation. The 96 wells plate received $100 \mu \mathrm{L}$ of the middle brook 7H9 broth and serial dilution of compounds was made directly on plate. The final drug concentrations tested were $100-0.2 \mu \mathrm{g} / \mathrm{mL}$ and compared with standards pyrazinamide $3.125 \mu \mathrm{g} / \mathrm{mL}$ and streptomycin $6.25 \mu \mathrm{g} / \mathrm{mL}$. Plates were covered and sealed with parafilm and incubated at $37^{\circ} \mathrm{C}$ for 5 days. After this time, $25 \mu \mathrm{L}$ freshly prepared 1:1 mixture of Alamar blue reagent and $10 \%$ tween- 80 was added to the plate and incubated for $24 \mathrm{~h}$. A blue color in the well was interpreted as no bacterial growth, and pink color was scored as growth. The MIC was defined as lowest drug concentration which prevented the color change from blue to pink. The results are shown in Table 2.

\section{RESULTS AND DISCUSSION}

\section{Chemistry}

In the present study, indolyl-pyrimidine derivatives were synthesized using the conventional method. A rapid, improved, and ecofriendly synthesis of thiopyrimidines is carried out through a one-pot multicomponent reaction of 5-chloro 2-phenyl indole3 -carboxaldehyde $1 \mathrm{a}$, ethyl cyanoacetate 2 , and thiourea 3 in the presence of ethanolic $\mathrm{K}_{2} \mathrm{CO}_{3}$ using the conventional method to give 1,2,3,4-tetrahydro-4-oxo-6-(5-chloro 2-phenyl-1H-indol-3-yl)-2thioxopyrimidine-5-carbonitrile $4 \mathrm{a}$. The compound $4 \mathrm{a}$ IR spectrum absorption peaks at 3340 and $3319 \mathrm{~cm}^{-1}$ which corresponding to the asymmetric stretching of 2 -NH group of pyrimidine, the peak appeared at $3101 \mathrm{~cm}^{-1}$ which corresponding to the indole- $\mathrm{NH}$, the sharp absorption peak appeared at $2170 \mathrm{~cm}^{-1}$ which corresponding to the nitrile function and the peak appeared at $1662 \mathrm{~cm}^{-1}$ due to the carbonyl group of pyrimidine nucleus. The IR absorption band at $1108 \mathrm{~cm}^{-1}$ which corresponds to the $\mathrm{C}=\mathrm{S}$ stretching supports the formation of compound $4 \mathrm{a} .{ }^{1} \mathrm{H}-\mathrm{NMR}$ spectrum data showed that the signal appeared as a singlet at $\delta 11.10$ which correspond to the indole $\mathrm{NH}$, the two singlet appeared $\delta 10.08$ and 10.01, ppm due to the two-NH protons of thiopyrimidine, respectively. The aromatic protons resonated as multiplet around $\delta 7.30-7.71 \mathrm{ppm}$, these proton NMR data support the formation of compound $4 \mathrm{a}$. Mass spectral data show that the isotopic peaks at $\mathrm{m} / \mathrm{z} 378.034\left(\mathrm{M}^{+}\right)$and $380.036\left(\mathrm{M}^{+}+2\right)$, which clearly confirm the formation of compound $4 \mathrm{a}$ (Scheme 1). Similarly, other compounds $4 \mathrm{~b}$ and $4 \mathrm{c}$ in the series were confirmed. The results were given in the material and method section.

\section{Antimicrobial activity}

Antimicrobial activity results (Table 1) the MIC value it is clear that the tested compounds were active in the concentration range of $62.5-250 \mu \mathrm{g} / \mathrm{mL}$ which is comparatively more or equipotent than the standards gentamycin and fluconazole. Antibacterial activity of

Table 1: In-vitro antimicrobial activities of compounds (4a-c)

\begin{tabular}{|c|c|c|c|c|c|c|c|c|}
\hline \multirow[t]{2}{*}{ Comp. code } & \multicolumn{4}{|c|}{ Antibacterial activity (MIC $\mu \mathrm{g} / \mathrm{mL}$ ) } & \multicolumn{4}{|c|}{ Antifungal activity (MIC $\mu \mathrm{g} / \mathrm{mL})$} \\
\hline & $E C^{\mathrm{a}}$ & $S A^{\mathbf{b}}$ & $K P^{c}$ & $P A^{\mathrm{d}}$ & $A O^{\mathrm{e}}$ & $A N^{\mathrm{f}}$ & $A F^{\mathrm{g}}$ & $A T^{\mathrm{h}}$ \\
\hline $4 a$ & 62.5 & 125 & 125 & 125 & 125 & 62.5 & 125 & 250 \\
\hline $4 b$ & 250 & 250 & 250 & 250 & 500 & 500 & 250 & 500 \\
\hline $4 c$ & 125 & 500 & 500 & 500 & 500 & 250 & 125 & 500 \\
\hline Gentamycin & 125 & 125 & 250 & 125 & -- & -- & -- & -- \\
\hline Fluconazole & -- & -- & -- & -- & 125 & 62.5 & 125 & 250 \\
\hline
\end{tabular}

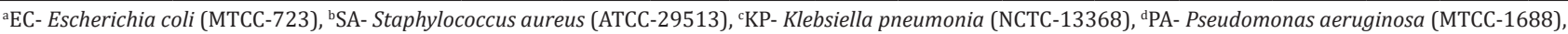

${ }^{e}$ AO- Aspergillus oryzae (MTCC-3567 ${ }^{\mathrm{T}}$, ${ }^{\mathrm{f}} \mathrm{AN}-$ Aspergillus niger (MTCC-281), ${ }^{\mathrm{g}}$ AF- Aspergillus flavus (MTCC-1973), ${ }^{\mathrm{h}}$ AT- Aspergillus terreus (MTCC-1782) 


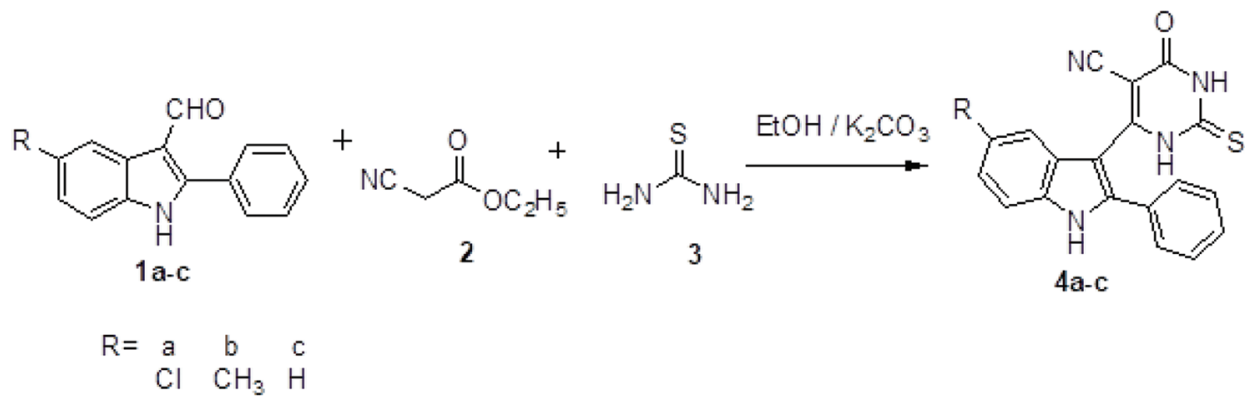

Scheme 1: Schematic pathways for synthesis of compounds (4a-c)

Table 2: Antitubercular activity of compounds (4a-c)

\begin{tabular}{ll}
\hline Comp. No. & MIC $^{\text {a }}$ values $(\mu \mathrm{g} / \mathbf{m L})$ \\
\hline $4 \mathrm{a}$ & 3.125 \\
$4 \mathrm{~b}$ & 25 \\
$4 \mathrm{c}$ & 12.5 \\
Pyrazinamide & 3.125 \\
Streptomycin & 6.25 \\
\hline
\end{tabular}

MIC: Minimum inhibitory concentration

screened samples, compound 4 a showed potent activity $(62.5 \mu \mathrm{g} / \mathrm{mL})$ against E. coli (MTCC-723).

Antifungal activity screening results revealed that the compound $4 \mathrm{a}$ showed potent activity $(62.5 \mu \mathrm{g} / \mathrm{mL})$ against $A$. niger (MTCC-281) and $(125 \mu \mathrm{g} / \mathrm{mL})$ K. pneumonia (NCTC-13368), this potent activity may be due to the presence of chlorine atom at C-5 position of indole system. Compound 4a exhibited equipotent activity against $S$. aureus (ATCC29513) and P. aeruginosa (MTCC-1688).

Antibacterial study revealed that the compound 4 a exhibited equipotent activity against all tested bacteria $A$. oryzae (MTCC-3567 ${ }^{\mathrm{T}}$ ), A. niger (MTCC-281), A. flavus (MTCC-1973), and A. terreus (MTCC-1782).

Screening studies have demonstrated that the newly synthesized compounds have promising antibacterial and antifungal properties. Therefore, it was concluded that there exists a better scope for further study on this class of compounds.

\section{Antitubercular activity}

The results of the antitubercular evaluation results are given in Table 2. Newly synthesized compounds (4a-c) were assayed for inhibitory activity toward M. tuberculosis H37Rv (ATCC2794). The MIC expressed as $\mu \mathrm{g} / \mathrm{mL}$ was determined for each compound.

The compound 4a showed excellent activity against $M$. tuberculosis H37 Rv (MIC $=3.125 \mu \mathrm{g} / \mathrm{mL}$ ) than the standards pyrazinamide and streptomycin ( $\mathrm{MIC}=3.125$ and $6.25 \mu \mathrm{g} / \mathrm{mL}$ ). The structure-activity relationship studies revealed that the presence of electron-withdrawing group chlorine at C-5 indole system may be attributed for enhanced antitubercular activity in the series and has emerged as promising antitubercular agents.

\section{CONCLUSION}

In the present study, indolyl-thiopyrimidine derivatives were synthesized using a conventional method. A rapid, improved, and eco-friendly synthesis of 1,2,3,4-tetrahydro-4-oxo-6-(5-substituted 2-phenyl-1H-indol-3-yl)-2-thioxopyrimidine-5-carbonitrile (4a-c). Screening studies have demonstrated that the newly synthesized compound 4a exhibited promising antimicrobial and antitubercular properties. Therefore, it was concluded that there exists a better scope for further study on this class of compounds.

\section{ACKNOWLEDGMENTS/FUNDING}

This work supported by UGC-BSR-Start-up Grant (F.No.30-478/2019). The author is thankful to the Principal, Sahyadri Science College, Shivamogga, for providing laboratory facilities, Chairman, Department of Biotechnology, SSCS, for providing facilities to carry out the antimicrobial activity, Principal, Maratha Mandal College, Belgaum for screening antitubercular activity, to the Director, Indian Institute of Technology, Chennai, for providing ${ }^{1} \mathrm{H}-\mathrm{NMR}$ and ${ }^{13} \mathrm{C}$ NMR and Mass spectra.

\section{AUTHORS' CONTRIBUTIONS}

The study was designed and executed, all the experimental section, results and discussion, and analysis section were performed, editing and reviewing were done by Dr. Prabhaker Walmik

\section{CONFLICTS OF INTEREST}

There are no conflicts to declare.

\section{REFERENCES}

1. Ansari KF, Lal C. Synthesis and biological activity of some heterocyclic compounds containing benzimidazole and beta-lactam moiety. J Chem Sci 2009; 121:1017-25.

2. Antus S, Gulácsi K, Juhász L, Kiss L, Kurtán T. Synthesis of naturally occurring o-heterocyclic compounds of biological activity. Pure Appl Chem 2004; $76: 1025-32$

3. Mostafa TB. Synthesis and modification of some heterocyclic compounds with potential biological activity coupled on poly (maleic anhydride-methyl methacrylate). J Am Sci 2010;6:512-24.

4. Singh AK, Mishra G, Jyoti K. Review on biological activities of 1,3,4-thiadiazole derivatives. J Appl Pharm Sci 2011;1:44-9.

5. Salimon J, Salih N, Hussien H, Yousif E. Synthesis and characterization of new heterocyclic compounds derived from 2-aminopyridine. Eur J Sci Res 2009;31:256-64.

6. Xu PF, Zhang ZH, Hui XP, Zhang ZY, Zheng RL. Synthesis of triazoles, oxadiazoles and condensed heterocyclic compounds containing cinchopheny and studies on biological activity of representative compounds. J Chin Chem Soc 2004;51:315-9.

7. Bagley MC, Lubinu MC. Microwave-assisted multicomponent reactions for the synthesis of heterocycles. J Heterocycl Chem 2006;1:31-58.

8. Biswa MS, Ravi Kumar BV, Jnyanaranjan P, Dinda SC. Ecofriendly and facile one-pot multicomponent synthesis of thiopyrimidines under microwave irradiation. J Nanopart 2013;2013:780786.

9. Misra U, Hitkari A, Saxena AK, Gurtu S, Shanker K. Biologically active indolylmethyl-1,3,4-oxadiazoles, 1,3,4-thiadiazoles, 4H--1,3,4triazoles and 1,2,4-triazines. Eur J Med Chem 1996;31:629-35.

10. Preeti R, Srivastava VK, Ashok KV. Synthesis and antiinflammatory activity of heterocyclic indole derivatives. Eur J Med Chem 2004;39:449-52

11. El-Gendy Adel A, Abdou Naida A, Sarhan El-Taher Z, El-Banna Hosney AY. Synthesis and biological activity of functionalized indole2-carboxylates, triazino- and pyridazino-indoles. Alex J Pharm Sci 1993;7:99-5

12. Kumar A, Saxena KK, Gurtu S, Sinha JN, Shanker K. Indole alkaloids have been proved to be medicinally important natural durg. Indian Drugs 1986;24:1-6. 
13. Yamamoto Y, Kurazono M. A new class of anti-MRSA and anti-VRE agents: Preparation and antibacterial activities of indole-containing compounds. Bioorg Med Chem Lett 2007;17:1626-8.

14. Süreyya O, Doğu N. Synthesis and biological evaluation of N-substituted indole esters as inhibitors of cyclo-oxygenase-2 (COX-2). Farmaco 2002;57:677-83.

15. Chen JJ, Wei Y, Williums JD, Drach JC, Townsend LB. Design, synthesis, and antiviral evaluation of some polyhalogenated indole C-nucleosides. Nucleosides Nucleotides Nucleic Acids 2005;24:1417-37.

16. Baba M, Pauwels R, Herdewijin P, Clerq DE, Desmyter J, Vandeputte M. Both 2',3'-dideoxythymidine and its 2',3'-unsaturated derivative (2',3'-dideoxythymidinene) are potent and selective inhibitors of human immunodeficiency virus replication in vitro. Biochem Biophys Res Commun 1987;142:128-34.

17. Sharma P, Rane N, Gurram VK. Synthesis and QSAR studies of pyrimido[4,5-d]pyrimidine-2,5-dione derivatives as potential antimicrobial agents. Bioorg Med Chem Lett 2004;14:4185-90.

18. Ito S, Masuda K, Kusano S. Pyrimidine derivative, process for preparing same and agricultural or horticultural fungicidal composition containing same. U S Patent 4 1991;988:704.

19. Ram VJ, Haque N, Guru PY. Chemotherapeutic agents XXV: Synthesis and leishmanicidal activity of carbazolylpyrimidines. Eur J Med Chem 1992;27:851-5.

20. Amir M, Javed SA, Kumar H. Pyrimidine as antiinflammatory agent: A review. Indian J Pharm Sci 2007;68:337-41.

21. Vega S, Alonso J, Diaz JA, Junquera F. Synthesis of 3-substituted-4phenyl-2-thioxo-1,2,3,4,5,6,7,8-octahydrobenzo[4,5]thieno[2,3-á] pyrimidines. J Heterocycl Chem 1990;27:269-73.

22. El-Kerdawy MM, Yousif Y, El-Emam AA, Moustafa MA, ElSherbeny MA. Synthesis and antiinflammatory activity of certain thienopyrimidine derivatives. Boll Chim Farm 1996;4:301-5.

23. Modica M, Santagati M, Santagati A, Cutuli V, Mangano N, Caruso A. Synthesis of new $[1,3,4]$ thiadiazolo[3,2-a] thieno[2,3-d]pyrimidinone derivatives with antiinflammatory activity. Pharmazie 2000;55:500-2.

24. Chambhare RV, Khadse BG, Bobde AS, Bahekar RH. Synthesis and preliminary evaluation of some $\mathrm{N}$-[5-(2-furanyl)-2-methyl-4-oxo-4Hthieno[2,3-d]pyrimidin-3-yl]-carboxamide and 3-substituted-5-(2furanyl)-2-methyl-3H-thieno[2,3-d]pyrimidin-4-ones as antimicrobial agents. Eur J Med Chem 2003;38:89-100.

25. Santagati NA, Caruso A, Cutuli VM, Caccamo F. Synthesis and pharmacological evaluation of thieno[2,3-d]pyrimidin-2,4-dione and 5H-pyrimido [5,4-b]indol-2,4-dione derivatives. Farmaco 1995;50:689-95.

26. Prabhaker W, Basavaraj SN, Swathi B, Somashekhar G. Design, synthesis of biologically active heterocycles containing indol- thiazolylthiazolidinone derivatives. Int J Pharm Pharm Sci 2018;6:113-7.

27. Prabhaker W, Saundane AR. Synthesis of novel indolyl-thiazolidinone derivatives as antioxidant, antimicrobial and atitubercular agents. Der Pharm Chem 2015;7:131-40.

28. Prabhaker W, Saundane AR. Synthesis of novel indolyl-azetidinone and thiazolidinone derivatives as a potent antioxidant, antimicrobial and antitubercular agents. Der Pharm Chem 2014;6:70-9.

29. Saundane AR, Yarlakatti M, Prabhaker W, Katkar V. Synthesis, antioxidant, antimicrobial, antimycobacterial, and cytotoxic activities of azetidinone and thiazolidinone moieties linked to indole nucleus. J Chem Sci 2012;124:469-81.

30. Saundane AR, Prabhaker W, Yarlakatti M, Katkar V, Vaijeenath AV. Synthesis and biological activities of some new annulated Pyrazolopyranopyrimidines and their derivatives containing indole nucleus. J Heterocycl Chem 2014;51:303-14.

31. Saundane AR, Prabhaker W, Kirankumar N M, Annapurna H. Synthesis of novel N-(aryl) diazenyl thiazol-2-amines and bezylidenethiazolidin4-ones linked to indole nucleus as antioxidant, antimicrobial, antimycobacterial and cytotoxic agents. Int J Pharm Pharm Sci 2014;6:141-7.

32. Saundane AR, Prabhaker W. Synthesis, antioxidant, antimicrobial, antimycobacterial, and cytotoxic activities of azetidinone and thiazolidinone moieties linked to indole nucleus. J Chem 2013;2013:543815.

33. Saundane AR, Prabhaker W. Synthesis, antimicrobial and antioxidant activities of some indole analogues containing naphthyridine and pyrimidonaphthyridine systems. Indian J Chem 2012;51B:1593-6.

34. Hiremath SP, Biradar JS, Purohit MG. A new route to indolo [3,2-b] isoquinolines. Indian J Chem 1982;21B:249-53.

35. National Committee for Clinical Laboratory Standards. M100 Performance Standards for Antimicrobial Susceptibility Testing: Twelfth Informational Supplement. Wayne, Pennsylvania: National Committee for Clinical Laboratory Standards; 2002.

36. Maria CS, De Souza MV, Alessandra CP, Marcelle LF, Raoni SB, Thais CM, et al. Evaluation of anti-tubercular activity of nicotinic and isoniazid analogues. ARKIVOC 2007;15:181-91. 